\title{
Recombinant tetra-cell adhesion motifs supports adhesion, migration and proliferation of keratinocytes/fibroblasts, and promotes wound healing
}

\author{
Mi-Yeon Jung ${ }^{1}$, Narendra Thapa ${ }^{1}$, Jung-Eun Kim², \\ Jung Duk Yang ${ }^{3}$, Byung Chae $\mathrm{Cho}^{3}$ \\ and In-San Kim ${ }^{1,4}$ \\ ${ }^{1}$ Department of Biochemistry and Cell Biology \\ Cell and Matrix Research Institute \\ ${ }^{2}$ Department of Molecular Medicine \\ School of Medicine, Kyungpook National University \\ Daegu 700-422, Korea \\ ${ }^{3}$ Department of Plastic and Reconstructive Surgery \\ Institute of Cell and Matrix Biology \\ School of Medicine, Kyungpook National University \\ Daegu 700-721, Korea \\ ${ }^{4}$ Corresponding author: Tel, 82-53-420-4821; \\ Fax, 82-53-422-1466; E-mail: iskim@ knu.ac.kr
}

Accepted 10 September 2007

Abbreviations: ECM, extracellular matrix; EPDIM, Glu-Pro-Asp-lleMet; FGF, fibroblast growth factor, FN, fibronectin; PHSRN, ProHis-Ser-Arg-Asn; RGD, Arg-Gly-Asp; VN, vitronectin

\begin{abstract}
An extracellular matrix protein plays an important role in skin wound healing. In the present study, we engineered a recombinant protein encompassing the $9^{\text {th }}$ and $10^{\text {th }}$ type III domains of fibronectin, and $4^{\text {th }}$ FAS 1 domain of $\beta$ ig-h3. This recombinant protein, in total, harbors four known-cell adhesion motifs for integrins: Pro-His-Ser-Arg-Asn (PHSRN) and Arg-Gly-Asp (RGD) in $9^{\text {th }}$ and $10^{\text {th }}$ type III domains of fibronectin, respectively, and Glu-Pro-Asp-Ile-Met (EPDIM) and Try-His $(\mathrm{YH})$ in $4^{\text {th }} \mathrm{FAS} 1$ domain of $\beta$ ig-h3, were designated to tetra-cell adhesion motifs (T-CAM). In vitro studies showed T-CAM supporting adhesion, migration and proliferation of different cell types including keratinocytes and fibroblasts. In an animal model of full-thickness skin wound, T-CAM exhibited excellent wound healing effects, superior to both $4^{\text {th }}$ FAS1 domain of $\beta$ ig-h3 or $9^{\text {th }}$ and $10^{\text {th }}$ type III domains of fibronectin. Based on these results, T-CAM can be applied where enhancement of cell adhesion, migration and proliferation are desired, and it could be developed into novel wound healing drug.
\end{abstract}

Keywords: $\beta$ IG-H3 protein; cell adhesion; cell movement; cell proliferation; fibronectin; wound healing

\section{Introduction}

Wound healing is essential process for organisms to regenerate the injured tissues. The cutaneous wound healing that follows injury to the skin and other soft tissues represents a dynamic and wellordered biological process (Martin, 1997). This requires integration of complex biological and molecular events of homeostasis, inflammation, epithelization, fibroplasia, extracellular matrix (ECM) deposition, angiogenesis, and tissue remodeling (Falanga, 2005). The fundamental processes like adhesion, migration and proliferation of keratinocytes/fibroblasts at wound play a key role for synthesis and reconstitution of injured cutaneous tissues. The deposition of provisional matrix comprising ECM proteins like collagens, fibronectin (FN), vitronectin (VN) and laminin-5 at wound bed and its remodeling are essential aspects of wound healing. These ECM proteins serve as substratum for migrating and proliferating keratinocytes and fibroblasts. In addition, various growth factors and cytokines (TGF- $\beta$, EGF, PDGF, FGF, ILs, INF) secreted and/or present in wound sites influence wound healing by promoting and/or regulating the activities of migrating/proliferating keratinocytes and fibroblasts (Singer and Clark, 1999; Werner and Grose, 2003).

$\mathrm{FN}$, an adhesive glycoprotein, is one of the components of initial plasma clot and provisional matrix at cutaneous injury sites and is involved in multistep process in wound healing and scar formation (Singer and Clark, 1999). It is a disulfide-linked dimer of identical $230-250 \mathrm{kDa}$ subunits, each subunit consists of three repeating domains: type I, type II, and type III domains (Pankov and Yamada, 2002). It is present in soluble dimeric form in plasma whereas in multimeric insoluble form in ECM. Several domains in FN are associated with various functions including cell adhesion, migration, proliferation, differentiation, chemotaxis, tissue-remodeling and wound healing (Grinnell, 1984; Pankov and Yamada, 2002). The specific sequences identified in FN, Pro-His-Ser-Arg-Asn (PHSRN) in $9^{\text {th }}$ and Arg-Gly-Asp (RGD) in $10^{\text {th }}$ type 
III repeats are recognized to interact with bewildering arrays of integrins including $\alpha 3 \beta 1, \alpha 5 \beta 1$, $\alpha \vee \beta 1, \alpha \vee \beta 3$ and $\alpha_{\| 1} \beta 3$ and mediate cell binding to FN (Pierschbacher and Ruoslahti, 1984; Grant et al., 1997; Li et al., 2003). These two sequences act synergistically to mediate cell adhesion.

Big-h3 is an FAS1 domain-containing matrix molecule, originally cloned by Skonier et al. (1994) from adenocarcinoma cells treated with TGF- $\beta$. It consists of EMI domain followed by tandem repeats of four FAS1 domains (each consisting of about 140 amino acids) which are similar to its prototype protein Drosophila fasciclin-I (Bastiani et al., 1987). The cell adhesion represents one of the functions of FAS1 domain-containing proteins like fasciclin I, periostin and $\beta$ ig-h3. The precise function of $\beta$ ig-h3 is not known yet but a number of studies suggest $\beta$ ig-h3 playing role in cell adhesion, migration, proliferation, differentiation, osteogenesis and wound healing (Kim et al., 2002; Park et al., 2004; Lee et al., 2006). At present, NKDIL in second, Glu-Pro-Asp-lle-Met (EPDIM) in fourth FAS1 domain and Try-His (YH) in each FAS1 domain are the known-cell adhesion motifs so far identified in $\beta$ ig-h3 and interact with various integrins mediating adhesion of cells to $\beta$ ig-h3 (Kim et al., 2000, 2002). The previous two integrinbinding sites are known to interact with $\alpha 3 \beta 1$ integrin and mediate the adhesion of keratinocytes to $\beta$ ig-h3 (Bae et al., 2002) whereas YH motif interacts with $\alpha v \beta 3 / 5$ integrins supporting the adhesion of various cell types including fibroblasts, endothelial cells and osteoblasts (Kim et al., 2002; Thapa et al., 2005). Although, role of $\beta$ ig-h3 in wound healing is obscure, its expression is observed in endothelium and stroma-derived cells in healing corneal wound (Rawe et al., 1997) and reactive astrocytes at stab wound sites in rat cerebral cortex (Yun et al., 2002). It is present in papillary dermis (LeBaron et al., 1995) and secreted by keratinocytes (Katz and Taichman, 1999). In vitro study shows $\beta$ ig-h3 supporting adhesion and migration of dermal fibroblasts and keratinocytes (LeBaron et al., 1995; Bae et al., 2002).

The defective wound healing is associated with various pathophysiologies including diabetes and uses of topical therapeutic agents have been proven beneficial. The soaking of wound dressing with $\mathrm{FN}$, preparing growth factors- and ECMcontaining topical formulations are reported to accelerate wound healing (Livant et al., 2002; Lariviere et al., 2003; Qiu et al., 2007). Moreover, the use of ECM proteins and their derivatives is common practice in tissue engineering (Badylak, 2002). With the aim of designing new recombinant protein endowed with multiple integrin-binding properties, we made hybrid molecule, T-CAM encompassing $9^{\text {th }}$ and $10^{\text {th }}$ type III domains of fibronectin and the $4^{\text {th }}$ FAS1 domain of $\beta$ ig-h3. The ability of T-CAM to support cell adhesion, migration and proliferation of cells was examined. Topical application of T-CAM and its wound healing effect were tested in full-thickness cutaneous wound model in rabbit.

\section{Materials and Methods}

\section{Generation of recombinant proteins}

Expression plasmid for wild type $\beta$ ig-h3 protein ( $\beta$ igh3-WT) is described previously (Kim et al., 2000). The fragment for fourth FAS1 domain (encoding amino acids 498-637) was obtained by PCR using $\beta$ ig-h3 cDNA, and cloned into the EcoRV site of pET-29b (designated to $\beta$ igh3 D-IV). The PCR fragment for 9th and 10th type III fibronectin domain was cloned into the EcoRV site of $\mathrm{pET}-29 \mathrm{~b}$ (designated to FN115). To generate T-CAM, above EcoRV fragment of FN was inserted into the EcoRV and Xhol sites of $\beta$ igh3 D-IV in pET-29b. All the constructs were confirmed by DNA sequencing. Recombinant proteins for all of these constructs were induced and purified as described previously (Kim et al., 2000).

\section{Western blot analysis}

Purified proteins $\beta$ igh3 D-IV, FN115 and T-CAM were separated through $12 \%$ SDS-PAGE gel (50 $\mathrm{ng}$ each) and transferred to polyvinylidine difluoride membrane. The membrane was blocked with $5 \%$ skim milk in TBS $(50 \mathrm{mM}$ Tris- $\mathrm{HCl}, \mathrm{pH}$ 7.4; $150 \mathrm{mM}$ $\mathrm{NaCl}$ ) for one $\mathrm{h}$ at room temperature and then incubated with His-probe HRP mouse monoclonal IgG (Santa Cruz Biotechnology, Inc) at the dilution of 1:4000 in TBS-T (TBS containing $0.05 \%$ Tween 20) for $1 \mathrm{~h}$ at room temperature. The membrane was extensively washed and the proteins were visualized with an enhanced chemiluminescence reagent (Amersham Pharmacia Biotech., Piscataway, NJ).

\section{Cell culture}

HaCaT and NIH3T3 cell lines were cultured in DMEM (Gibco-BRL) with $4.5 \mathrm{~g} / \mathrm{L}$ glucose, $10 \%$ FBS and antibiotics at $37^{\circ} \mathrm{C}$ in $5 \% \mathrm{CO}_{2}$. The normal human fibroblast cells were grown in DMEM medium supplemented with $4.5 \mathrm{~g} / \mathrm{L}$ glucose, $10 \%$ fetal calf serum and antibiotics. Normal human keratinocytes (NHEK) were grown in keratinocyte 
medium kit (KMK, Sigma). CHO cells were grown in Minimum Essential Medium-Alpha ( $\alpha-M E M)$ and MRC5 cells were grown in RPMI- 1640 with $4.5 \mathrm{~g} / \mathrm{L}$ glucose, $10 \%$ FBS and antibiotics at $37^{\circ} \mathrm{C}$ in $5 \%$ $\mathrm{CO}_{2}$.

\section{Cell adhesion and spreading assay}

The cell adhesion assay was performed as described previously (Kim et al., 2000). Briefly, 96-well micro-plates (Falcon, Becton-Dickinson, Mountain View, CA) were coated with protein by incubating at $37^{\circ} \mathrm{C}$ for $1 \mathrm{~h}$ and then blocked with PBS-containing $0.2 \%$ BSA for $1 \mathrm{~h}$ at $37^{\circ} \mathrm{C}$. The different proteins used for coating were as follows: $\beta$ igh3-WT, $\beta$ igh3 D-IV, purified human plasma fibronectin (pFN), FN115, T-CAM, and heat-inactivated BSA (Sigma). Cells were trypsinized and suspended in the culture media at a density of 2.5 $\times 10^{4}$ cells $/ \mathrm{ml}$ and $0.1 \mathrm{ml}$ of the cell suspension was then added to each well of the plates. Cell attachment was analyzed as follows. After incubation for $1 \mathrm{~h}$ at $37^{\circ} \mathrm{C}$, unattached cells were removed by rinsing twice with PBS. Attached cells were incubated for $1 \mathrm{~h}$ at $37^{\circ} \mathrm{C}$ in $50 \mathrm{mM}$ citrate buffer, pH 5.0, containing $3.75 \mathrm{mM}$ p-nitrophenyl$\mathrm{N}$-acetyl $\beta$-D-glucosaminide (hexosaminidase substrate) and $0.25 \%$ Triton X-100. Enzyme activity was blocked by addition of $50 \mathrm{mM}$ glycine buffer, $\mathrm{pH} 10.4$, containing $5 \mathrm{mM}$ EDTA, and the absorbance was measured at $405 \mathrm{~nm}$ in a Multiscan $\mathrm{MCC} / 340$ microplate reader (Titertek Instruments, Inc., Huntsville, AL).
For spreading assay, cells were applied into 96-well culture plates-coated with proteins as described above. The attached cells were fixed with $8 \%$ glutaraldehyde (Sigma) and then stained with $0.25 \%$ crystal violet (Sigma) in $20 \%$ methanol $(\mathrm{w} / \mathrm{v})$. Cell area was measured using Image-Pro plus software (Media Cybernetics, Silver Spring, $\mathrm{MD}$ ). Experiments were repeated in triplicate with 200 or 300 measurements per site for each experiment. Data are reported as the mean area at specific time point \pm S.E.

\section{Migration assay}

Cell migration assay was performed in trans-well plates $(8 \mu \mathrm{m}$ pore size, Costar, Cambridge, MA). The undersurface of the transwell-membrane were coated by incubating in protein-containing PBS at $4^{\circ} \mathrm{C}$ for overnight, and blocked with $2 \%$ BSA. The fibroblast $\left(1 \times 10^{4}\right.$ cells $)$ and HaCaT $\left(1 \times 10^{5}\right.$ cells) per well in $200 \mu \mathrm{l}$ medium were seeded in the upper compartment of filters. After $2 \mathrm{~h}$ and $24 \mathrm{~h}$ of migration, cells in the upper chamber of the filter were removed and nonmigrating cells on the top of the filters were removed with a cotton swab. Cells on the lower side of the filter were fixed with $8 \%$ glutaraldehyde and then stained with $0.25 \%$ crystal violet in $20 \%$ methanol $(\mathrm{w} / \mathrm{v})$. Each experiment was repeated in duplicate and within each well, cell counting was done in nine randomly selected microscopic high power fields (HPF $\times 200)$.
A
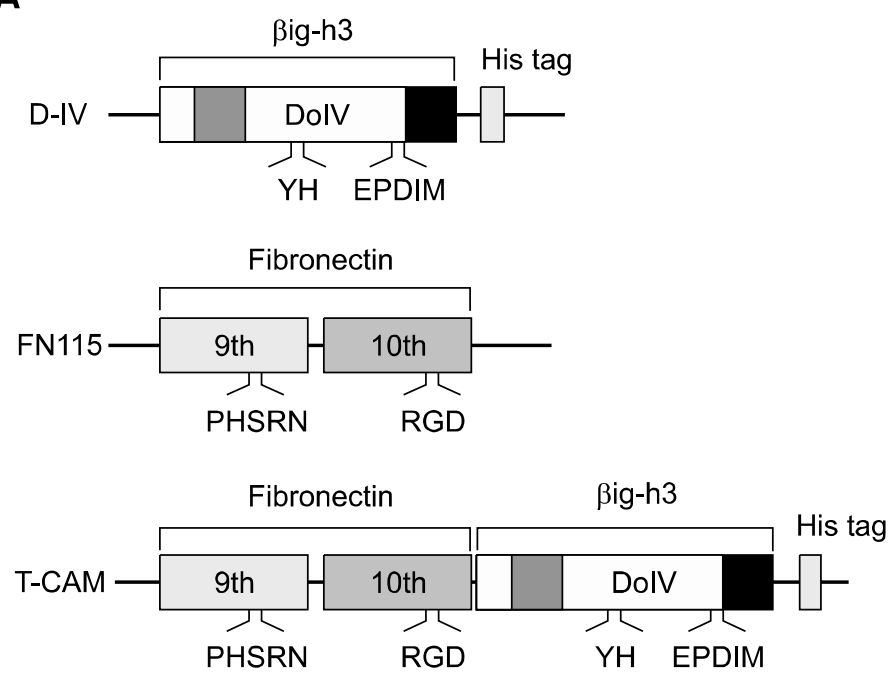

B

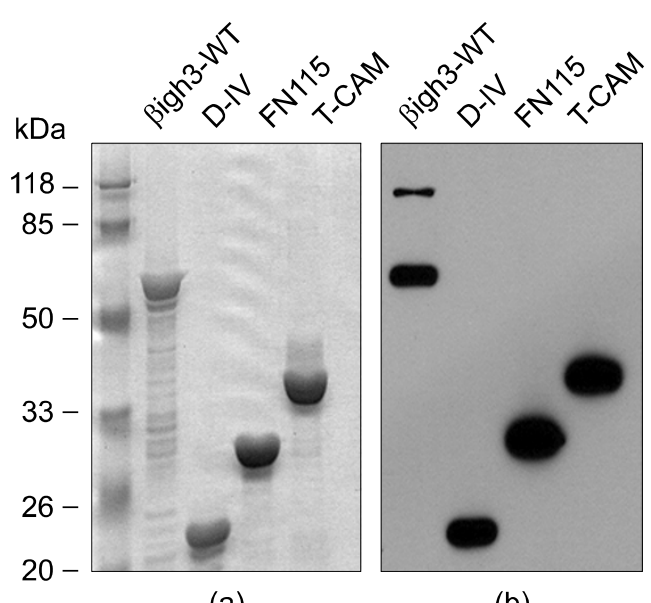

(a) (b)

Figure 1. Schematic diagram of $\beta$ igh3 D-IV, FN115 and T-CAM. A, Positions of YH and EPDIM motifs in $\beta$ igh3 D-IV are shown. The $9^{\text {th }}$ and $10^{\text {th }}$ FN type III domain (FN115) contain PHSRH and RGD motif, respectively. The T-CAM consists of N-terminus FN115 and C-terminus FAS1 domain. B, The purity and integrity of protein used are shown by SDS-PAGE (a) and western blotting using anti-his antibody (b). 


\section{Proliferation assay}

Twenty-four-well culture plates were coated with the indicated proteins diluted in PBS, for overnight at $4^{\circ} \mathrm{C}$. The plates were rinsed three times with PBS and uncoated surfaces were blocked with $2 \%$ BSA in PBS for $1 \mathrm{~h}$ at $37^{\circ} \mathrm{C}$. Then, plates were rinsed and keratinocytes prepared by $0.25 \%$ trypsin-EDTA treatment, were added to each well in $1 \mathrm{ml}$ culture medium. Although the initial cell adhesion efficiency was different depending on the substrate used, most of the cells became adherent within a few hours, thus, giving the same cell numbers. The cell proliferation was assessed by manual cell counting in hematocytometer at the interval of $24 \mathrm{~h}$ for total $96 \mathrm{~h}$. Cell numbers at $0 \mathrm{~h}$ indicate numbers at $24 \mathrm{~h}$ after initial cell seeding, showing that there were no differences in the initial cell numbers at $0 \mathrm{~h}$ point among different conditions.

\section{Full-thickness skin wound preparation and treatment}

The dorsal skin of the New Zealand white rabbits were shaved and cleaned with iodine solution, and a full-thickness skin wound (approximately $30 \mathrm{~mm}$ in diameter) were created (Saaristo et al., 2006). Then, wounds were treated with the cream con-
A

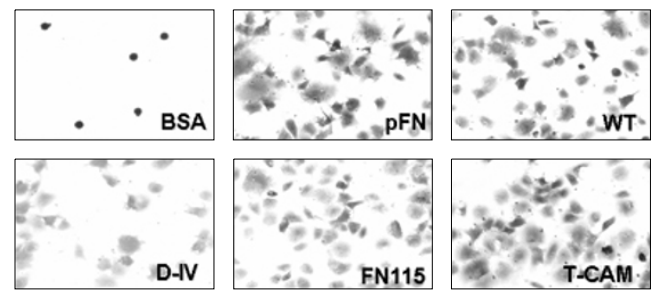

C

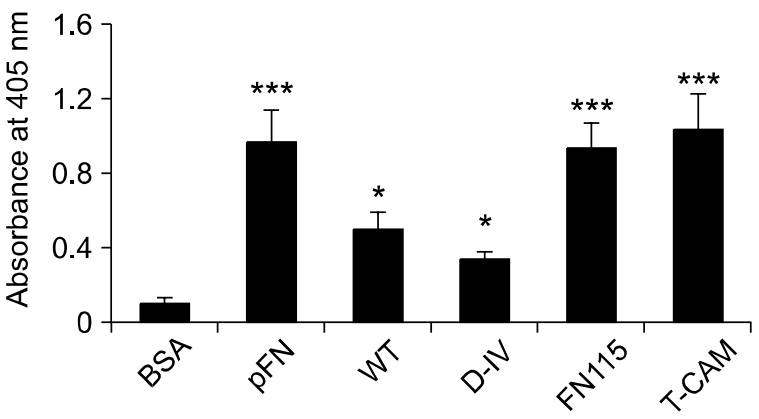

E

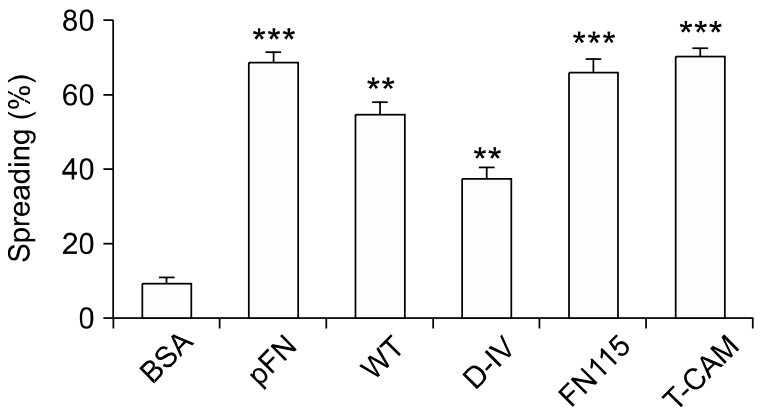

B

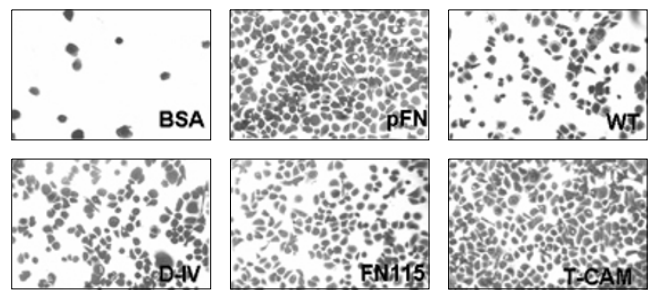

D

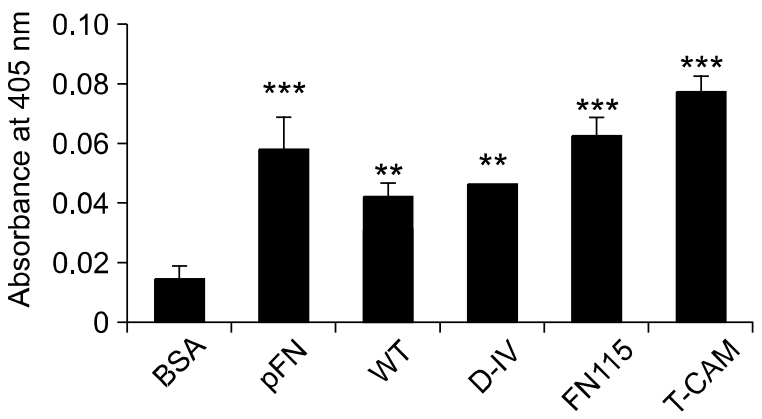

F

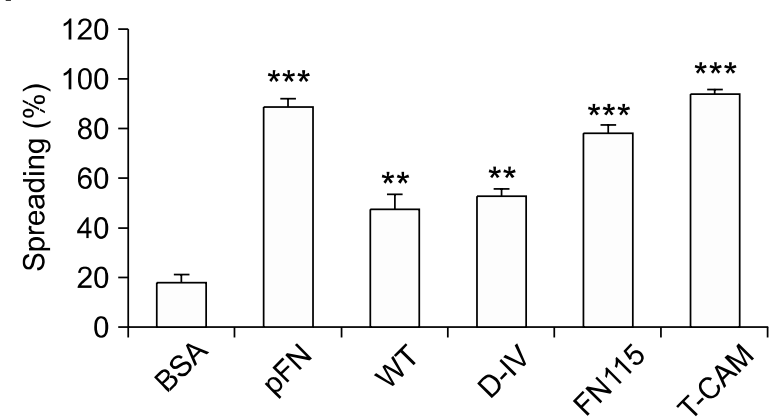

Figure 2. T-CAM supports adhesion and spreading of fibroblast and HaCaT cells. A, Low power microscopic picture of adhering fibroblasts (A) and $\mathrm{HaCaT}$ cells (B) to various proteins are shown. The cell adhesion assay was carried out in 96-well plate pre-coated with various proteins and number of cells adhering was quantified by enzymatic method as described in "Materials and Methods". C, fibroblasts, D, HaCaT. BSA was used as negative control and other proteins used were pFN, Bigh3-WT, FN115, and T-CAM. Spreading of cells to above proteins and their measurement are shown in E (fibroblasts) and $\mathrm{F}$ (HaCaT cells). Data represent mean $\pm \mathrm{SD}$ of three separate experiments. ${ }^{*} P<0.05$, ${ }^{* *} P<0.01$ and ${ }^{* * *} P<0.001$ 
taining various recombination proteins, $\beta$ igh3-WT, $\beta$ igh3 D-IV, FN115, and T-CAM (500 $\mu$ g each) and covered with a permeable adhesive dressing. The dressing was removed on day 3 after wounding to enable visual analysis. Digital photographs of the dorsal wounds were taken every 3 days, and the wound areas were calculated as a percentage of the original wound. Sixty rabbit with paired wounds were analyzed for each time point.

\section{Statistical analysis}

All data were expressed as means \pm SEM. Comparisons among group were performed using one or two-way ANOVA. ${ }^{*} P<0.05,{ }^{* *} P<0.01$ and ${ }^{* * *} P<0.001$ were considered to be statistically significant.

\section{Results}

\section{T-CAM supports adhesion and spreading of cells}

The schematic diagram of $\beta$ igh3 D-IV, FN115 and T-CAM are shown in Figure $1 \mathrm{~A}$. The purity and integrity of each protein used were assessed by
SDS-PAGE/Coomassie staining (Figure 1B-a) and western blotting using his-tag antibody (Figure 1B-b). The expected sizes of proteins are: $68 \mathrm{kDa}$ ( $\beta$ ig-h3), $21 \mathrm{kDa}$ ( $\beta$ igh3 D-IV), $27 \mathrm{kDa}$ (FN115) and $45 \mathrm{kDa}$ (T-CAM). The microscopic picture of fibroblast and $\mathrm{HaCaT}$ cells adhering to these proteins are shown in Figure $2 \mathrm{~A}$ and $2 \mathrm{~B}$, respectively. The cell adhesion assay showed remarkably high cell adhesion activity of T-CAM for these cells when compared with $\beta$ ig-h3 and its FAS1 domain (Figure 2C and 2D). However, its cell adhesion activity was comparable with that of FN or FN115, and no significant increase in its cell adhesion activity was observed even with inclusion FAS1 domain.

The cell adhesion and spreading are intimately associated processes and involves the complex rearrangements of the actin cytoskeleton in spreading cells. The number and surface areas of fibroblast and $\mathrm{HaCaT}$ cells that adhered and spread to T-CAM were clearly greater than those adhered and spread to BSA, $\beta$ igh3-WT or $\beta$ igh3 D-IV (Figure 2E and 2F). Like cell adhesion, cell spreading of these cells to T-CAM was comparable to FN or FN115 and no further enhancement in spreading activity of T-CAM was observed.
A

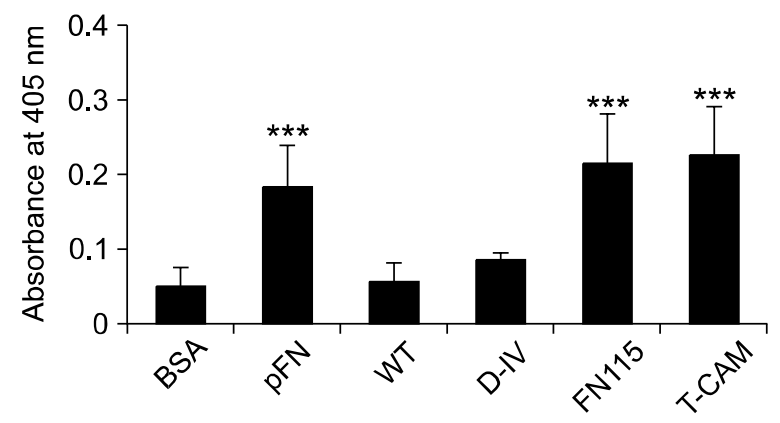

C

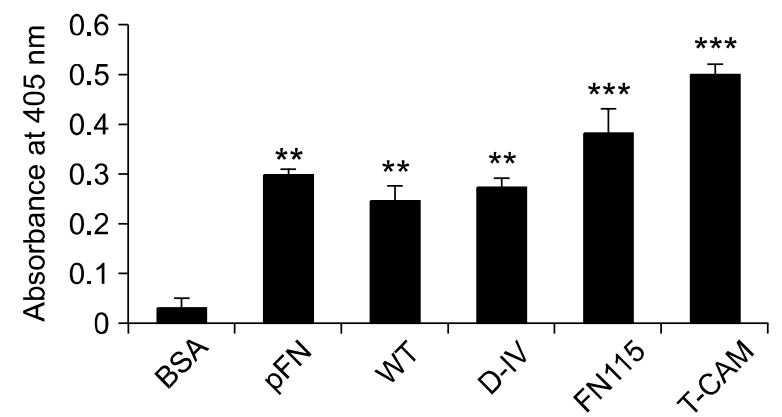

B

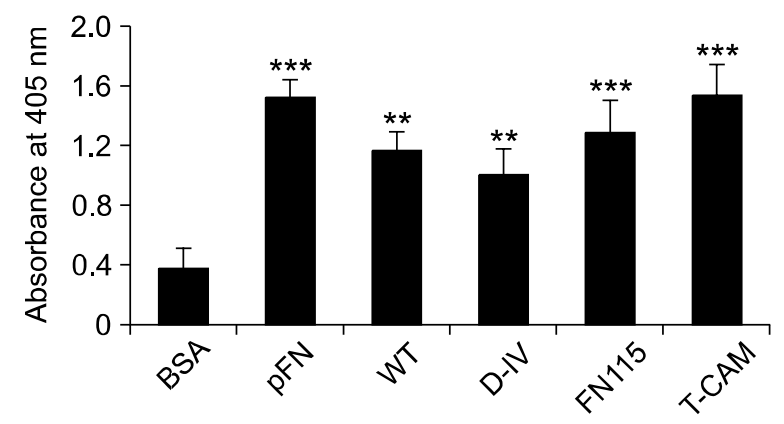

D

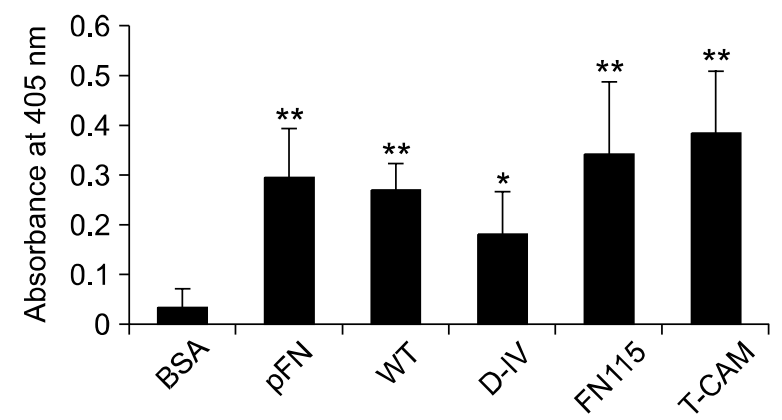

Figure 3. T-CAM supports adhesion of various cell types. Cell adhesion assay was performed as described above and various cell types used are A (CHO cells), B (MRC5 cells), C (NHEK cells), and D (NIH3T3 cell). Data represent mean $\pm \mathrm{SD}$ of three separate experiments. ${ }^{\star} P<0.05,{ }^{* \star} P<0.01$ and ${ }^{* * *} P<0.001$ 
The cell adhesion activity of T-CAM was tested for a number of other cell lines including Chineses hamster ovary ( $\mathrm{CHO}$ ), lung fibroblast (MRC5), normal human keratinocyte (NHEK) and mouse fibroblast (NIH3T3). As shown in Figure 3, T-CAM is equally active in supporting the adhesion of these cell lines. It was expected because four known-cell adhesion motifs present in T-CAM are supposed to interact with a large numbers of integrins and can mediate adhesion of these cell types.

\section{T-CAM support proliferation of fibroblast and $\mathrm{HaCaT}$ cells}

The various ECM proteins in concert with growth factors show mitogenic property on adhering cells by providing the necessary intracellular signaling. The fibroblast and HaCaT cells synchronized by serum starvation were seeded onto plates coated with T-CAM or other proteins and allowed to grow. The cell proliferation assessed by manual cell counting showed that growth rate of these cells seeded onto cultured plates coated with T-CAM and other proteins were higher than the growth rate of the cells seeded onto culture plates coated with BSA (Figure 4). However, growth promoting activities for T-CAM, FN, FN115, $\beta$ igh3-WT and D-IV were more or less similar. Previous studies have also demonstrated growth promoting activities of $\mathrm{pFN}, \beta \mathrm{ig}-\mathrm{h} 3$ and its FAS1 domain (Bae et al., 2002).

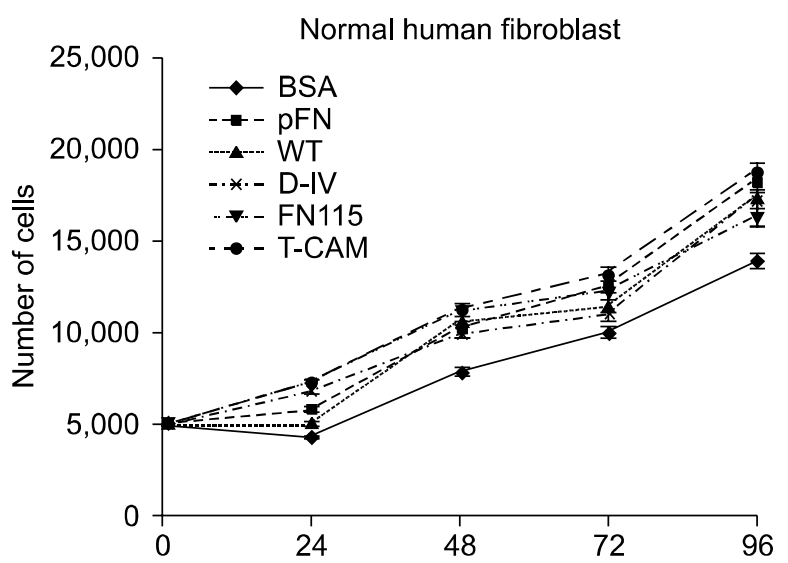

(h)

\section{T-CAM enhances fibroblast and HaCaT cells migration}

Migration promoting activity of T-CAM was desirable as migration of keratinocytes and fibroblasts from the vicinity of wound is crucially required during wound healing. To test whether T-CAM could mediate fibroblast and $\mathrm{HaCaT}$ cells migration, we employed transwell plate migration assay. Cells were seeded onto transwells coated with T-CAM or other proteins. The cells started to migrate through the T-CAM-coated filter within $6 \mathrm{~h}$ of cell seeding. The microscopic pictures of migrating cells are shown in Figure $5 \mathrm{~A}$ and $\mathrm{B}$. The quantitaion of migrating cells showed profoundly greater migration-promoting activity of T-CAM compared with other proteins used for both types of cells (Figure $5 \mathrm{C}$ and $\mathrm{D}$ ).

\section{T-CAM accelerates wound closure}

After testing for cell adhesion, proliferation and migration of cells to T-CAM, in vivo test was conducted to test its effect on cutaneous wound healing in rabbit. The paired full-thickness skin wounds in the back skin of the rabbit were covered with cream-containing T-CAM or other proteins. As shown in Figure 6, T-CAM-treated wounds showed significantly accelerated repair when compared with $\beta$ igh3-WT, $\beta$ igh3 D-IV or FN115 treated wounds. T-CAM treated wounds showed 93\% reduction in wound size by day 12 whereas $\beta$ igh 3 D-IV and FN115-treated wounds had $87 \%$ and $82 \%$ reduction in wound size by day 12 , respectively.

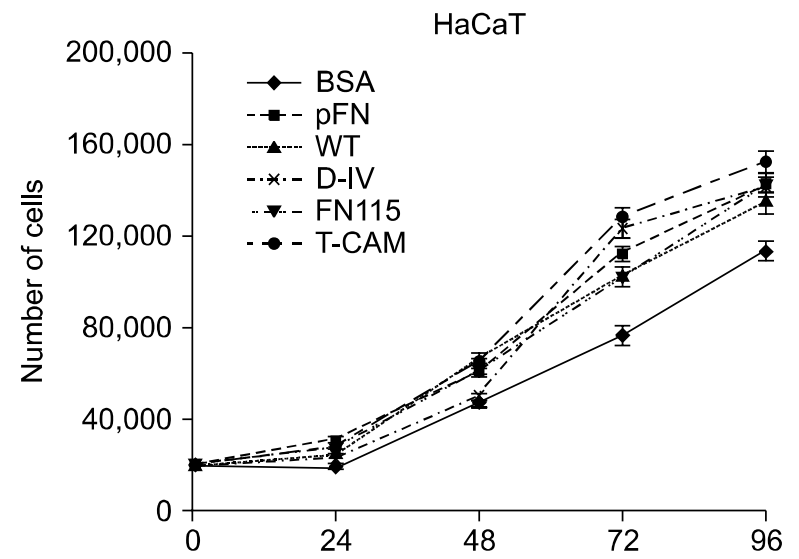

(h)

Figure 4. T-CAM supports proliferation of normal human fibroblast and HaCaT cells. The 24-well cultured plates were coated with either of proteins: BSA, pFN, $\beta$ igh3-WT, FN115 or T-CAM. The normal human fibroblasts $\left(5 \times 10^{3}\right.$ cells $)$ and HaCaT cells $\left(1 \times 10^{4}\right.$ cells $)$ were seeded in serum-containing medium and cell numbers were counted at $24,48,72$ and $96 \mathrm{~h}$ after the cell seeding by manual cell counting methods. The results were derived from three independent experiments, with duplicated in each experiment. 
A
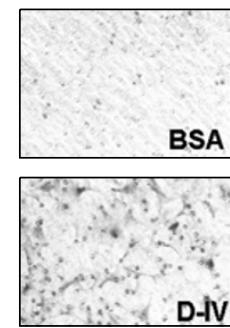

D-IV
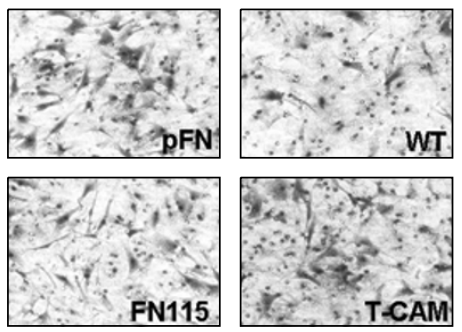

C

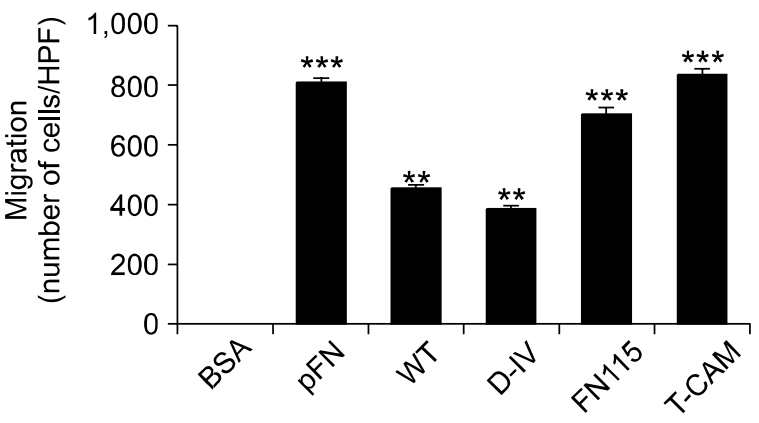

B
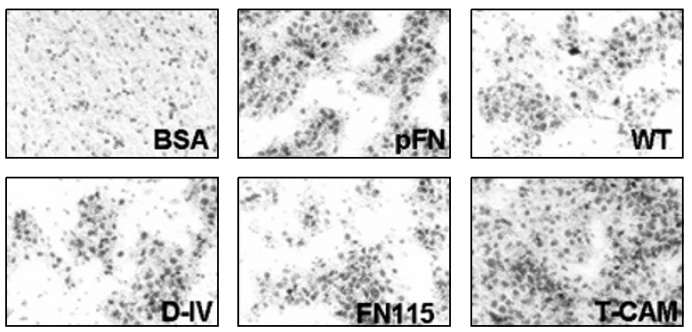

D

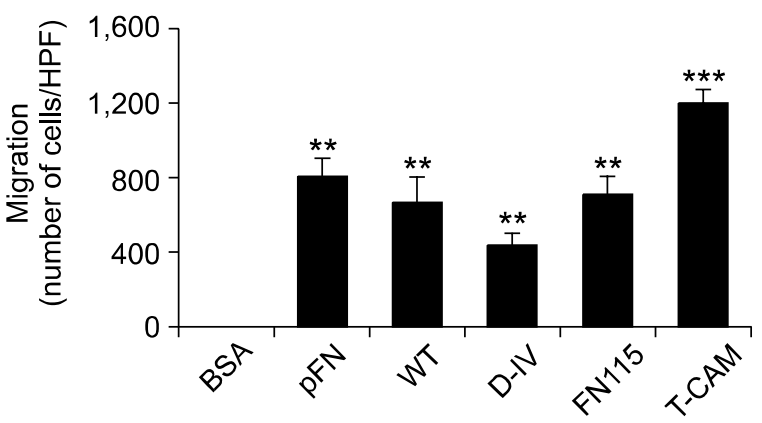

Figure 5. Migration-promoting effect of T-CAM. The transwell membranes were pre-coated with various proteins as described above. Fibroblast and keratinocyte cells were seeded and allowed to migrate for $2 \mathrm{~h}$ and $24 \mathrm{~h}$ through transwell plates and migrating cells were quantified as described in "Materials and Methods". Data represent mean \pm SD of three separate experiments. ${ }^{*} P<0.05,{ }^{* *} P<0.01$ and ${ }^{* * *} P<0.001$

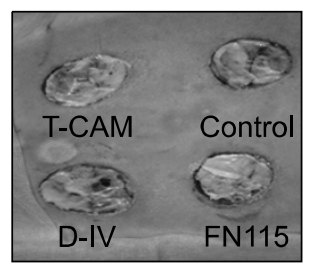

Day 1

Day 6

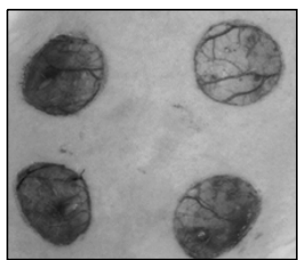

Day 12
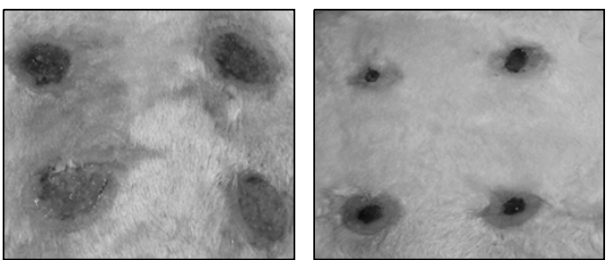

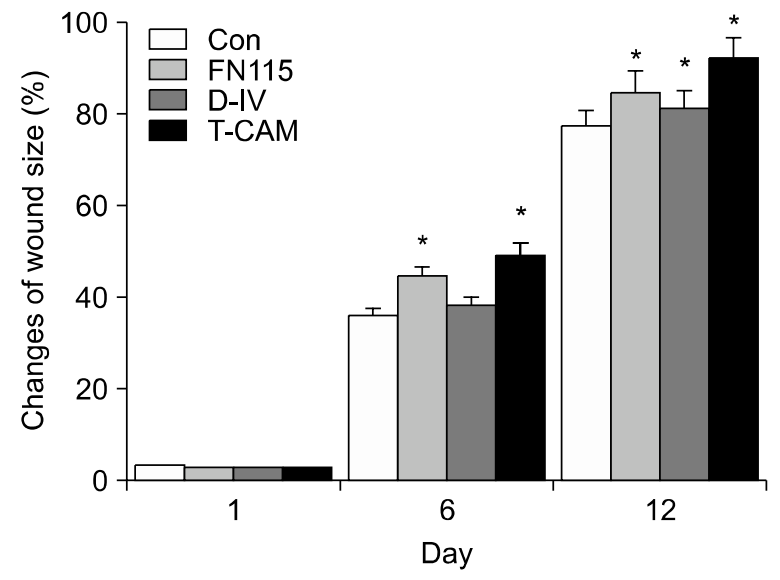

Figure 6. T-CAM promotes the wound healing. Wound was made on dorsal area of a rabbit. T-CAM, $\beta$ igh3 D-IV and FN115 were applied to the wounds at final concentration of $500 \mu \mathrm{g} / \mathrm{ml}$. Wound closure was measured on days 1,6 , and 12 after wounding. ${ }^{*} P<0.05$ was considered to be statistically significant. 


\section{Discussion}

The specific purpose of this study was to examine the beneficial aspect of topical application of protein endowed with multiple integrin-binding sites in cutaneous wound healing process. For this purpose, T-CAM was designed by combining the $9^{\text {th }}$ and $10^{\text {th }}$ type III domain of FN and $4^{\text {th }}$ FAS1 domain of $\beta$ ig-h3. This new fusion protein, T-CAM harbors, in total, four well known-integrin binding sites: PHSRN in $9^{\text {th }}$ and RGD in $10^{\text {th }}$ type III fibronectin domain, and EPDIM and YH in $4^{\text {th }}$ FAS1 domain of $\beta$ ig-h3. The PHSRN and RGD motifs in $\mathrm{FN}$ are known to act synergistically in mediating cell adhesion (Grant et al., 1997). The EPDIM in $4^{\text {th }}$ FAS1 domain is known to mediate $\alpha 3 \beta 1$ integrinmediated adhesion of human corneal epithelial cells and keratinocytes to $\beta$ ig-h3 (Kim et al., 2000; Bae et al., 2002). The $\mathrm{YH}$ motif which is present in all four FAS1 domains of $\beta$ ig-h3 is active in mediating adhesion of fibroblasts (Kim et al., 2002). We hypothesized that inclusion of these integrin-binding sites will enable T-CAM to interact with diverse repertoire of integrins, specially, those expressed in migrating and transmigrating cells at wound healing sites. Migrating keratinocytes/ fibroblasts at the vicinity of wounds are known to show enhanced expression of already existing or new integrins that will enable them to interact with various ECM proteins present at wound sites (Santoro and Gaudino, 2005). The reason for selecting integrin-binding domains of FN is supported by the fact that $\mathrm{FN}$ is a major constituent of provisional matrix proteins at wound healing sites and its role in wound healing is supported by a numbers of studies (Lariviere et al., 2003). Although, $\beta$ ig-h3 is reported to be expressed in healing corneal wound (Rawe et al., 1997) and reactive astrocytes at stab wound sites in rat cerebral cortex, its precise role in wound healing process is yet to be known.

As a new fusion protein from two well-known ECM proteins, FN and $\beta$ ig-h3, the ability of T-CAM to support the adhesion, migration and proliferation of cells was examined. The T-CAM showed remarkable cell adhesion activity supporting the adhesion of different cell types including keratinocytes and fibroblasts. As expected, cell adhesion activity was higher than that of pFN, FN115, $\beta$ igh3WT and $\beta$ igh3 D-IV. The ability of T-CAM to support the adhesion of different cell types was conceivable because T-CAM constitute four wellknown integrin binding sites that can interact with diverse family of integrins. However, we did not examine functional contribution of specific integrin mediating the adhesion of neither of these cells to
T-CAM. We do not know whether T-CAM retains the integrin-specificity of its parent molecules and if there is change in integrin specificity and affinity because of fusion of two distinct domains.

Keratinocytes migration and epithelization over provisional matrix composed of fibrin and $\mathrm{FN}$ is an essential process of wound healing (Guo et al., 1990; Zhang and Kramer, 1996; Putnins et al., 1999; Yamada, 2000). We tested migration-promoting activity of T-CAM for keratinocytes and fibroblasts because migration of these cells is required for wound healing. The T-CAM support migration of fibroblast and $\mathrm{HaCaT}$ cells and quantitation of migrating cells to T-CAM was clearly higher than to pFN, FN115, $\beta$ igh3 and D-IV.

In the context of wound healing, the synergy between integrin, ECM and growth factors is one of the key factors in the regulation of tissue regeneration. The ligation of ECM by integrins is known to regulate/amplify the intracellular signaling of growth factors that are intimately associated with wound healing processes. As a cell adhesion substrate, T-CAM support proliferation of both keratinocytes and fibroblasts in a serum-free condition. The mitogenic and proliferative activity is generally expected for many ECM proteins.

In vivo study was performed to test the wound healing effect of the T-CAM in a full-thickness cutaneous wound model in rabbit. This represents the most common and simplest model of wound repair mimicking that of human (Greenhalgh, 2005). In previous studies, the topical application of FN and short peptide PHSRN derived from FN has been reported to promote the wound healing in the genetically obese diabetes model (Livant et al., 2002; Qiu et al., 2007). The various peptides derived from ECM proteins such as collagen type IV and laminin and with increased adhesion, motility and chemotaxis effects are sought to develop into wound healing topical formulations (Rosso et al., 2005). We found more effective wound healing in T-CAM-treated groups than FN115 and $\beta$ igh3 D-IV-treated groups. It is likely that adhesion, migration and proliferation-promoting effect of T-CAM might be the underlying molecular clues that account for the wound healing effect of T-CAM.

In conclusion, T-CAM may represent a novel fusion protein from two prevalent and distinct ECM proteins, FN and $\beta$ ig-h3, that could be developed into wound healing drug.

\section{Acknowledgments}

This work was supported by Advanced Medical Technology Cluster for Diagnosis and Prediction and Brain Korea 21 
programs.

\section{References}

Badylak AF. The extracellular matrix as a scaffold for tissue reconstrction. Seminars in Cell Developmental Biol 2002; 13:377-83

Bae JS, Lee SH, Kim JE, Choi JY, Park RW, Yong Park J, Park HS, Sohn YS, Lee DS, Bae Lee E, Kim IS. Betaig-h3 supports keratinocyte adhesion, migration, and proliferation through alpha3beta1 integrin. Biochem Biophys Res Commun 2002; 294:940-8

Bastiani MJ, Harrelson AL, Snow PM, Goodman CS. Expression of fasciclin I and II glycoproteins on subsets of axon pathways during neuronal development in the grasshopper. Cell 1987;48:745-55

Falanga V. Wound healing and its impairment in diabetic foot. Lancet 2005;366:1736-43

Grant RP, Spitzfaden C, Altroff H, Campbell ID, Mardon HJ. Structural requirements for biological activity of the ninth and tenth FIII domains of human fibronectin. J Biol Chem 1997;272:6159-66

Greenhalgh DG. Models of wound healing. J Burn Care Rehabil 2005;26:293-305

Grinnell F. Fibronectin and wound healing. J Cell Biochem 1984;26:107-16

Guo M, Toda K, Grinnell F. Activation of human keratinocyte migration on type I collagen and fibronectin. J Cell Sci 1990;96:197-205

Katz AB, Taichman LB. A partial catalogue of proteins secreted by epidermal keratinocytes in culture. $\mathrm{J}$ Invest Dermatol 1999;112:818-25

Kim JE, Kim SJ, Lee BH, Park RW, Kim KS, Kim IS Identification of motifs for cell adhesion within the repeated domains of transforming growth factor-beta-induced gene, betaig-h3. J Biol Chem 2000;275:30907-15

Kim JE, Jeong HW, Nam JO, Lee BH, Choi JY, Park RW, Park JY, Kim IS. Identification of motifs in the fasciclin domains of the transforming growth factor-beta-induced matrix protein betaig-h3 that interact with the alphavbeta5 integrin. J Biol Chem 2002; 277:46159-65

Lariviere B, Rouleau M, Picard S, Beaulieu AD. Human plasma fibronectin potentiates the mitogenic ctivity of platelet-derived grwoth factor and complements its wound healing effects. Wound Rep Reg 2003;11:79-89

LeBaron RG, Bezverkov KI, Zimber MP, Pavelec R, Skonier $\mathrm{J}$, Purchio AF. Beta IG-H3, a novel secretory protein inducible by transforming growth factor-beta, is present in normal skin and promotes the adhesion and spreading of dermal fibroblasts in vitro. J Invest Dermatol 1995;104:844-9

Lee BH, Bae JS, Park RW, Kim JE, Park JY, Kim IS. Betaig-h3 triggers signaling pathways mediating adhesion and migration of vascular smooth muscle cells through alphavbeta5 integrin. Exp Mol Med 2006;38:153-63
Livant DL, Brabec RK, Kurachi K, Allen DL, Wu Y, Haaseth $\mathrm{R}$, Andrews P, Ethier SP, Markwart S. The PHSRN sequence induces extracellular matrix invasion and accelerates wound healing in obese diabetic mice. J Clin Invest 2002;105:153745

Li F, Redick SD, Erickson HP, Moy VT. Force measurements of the alpha5beta1 integrin fibronectin interaction. Biophys J 2003;84:1252-62

Martin P. Wound healing-aiming for perfect skin regeneration. Science 1997;276:75-81

Pankov R, Yamada KM. Fibronectin at a glance. J Cell Sci 2002;115:3861-3

Park SW, Bae JS, Kim KS, Park SH, Lee BH, Choi JY, Park JY, Ha SW, Kim YL, Kwon TH, Kim IS, Park RW. Beta ig-h3 promotes renal proximal tubular epithelial cell adhesion, migration and proliferation through the interaction with alpha3beta1 integrin. Exp Mol Med 2004;36:211-9

Pierschbacher MD, Ruoslahti E. Cell attachment activity of fibronectin can be duplicated by small synthetic fragments of the molecule. Nature 1984;309:30-3

Putnins EE, Firth JD, Lohachitranont A, Uitto VJ, Larjava H. Keratinocyte growth factor (KGF) promotes keratinocyte cel attachment and migration on collagen and fibronectin. Cell Adhes Commun 1999;7:211-21

Qiu Z, Kwon AH, Kamiyama Y. Effects of plasma fibronectin on the healing of full-thickness skin wounds in streptozotocininduced diabetic rats. J Surg Res 2007;138:64-70

Rawe IM, Zhan Q, Burrows R, Bennett K, Cintron C. Beta-ig. Molecular cloning and in situ hybridization in corneal tissues. Invest Ophthalmol Vis Sci 1997;38:893-900

Rosso F, Marino G, Giordano A, Barbarisi M, Parmeggiani $D$, Barbarisi A. Smart materials as scaffolds for tissue engineering. J Cellular Phys 2005;203:465-70

Saaristo A, Tammela T, Farkkila A, Karkkainen M, Suominen $\mathrm{E}$, Yla-Herttuala S, Alitalo K. Vascular endothelial growth factor-C accelerates diabetic wound healing. Am J Pathol 2006;169:1080-7

Santoro MM, Gaudino G. Cellular and molecular facets of keratinocyte reepithelization duringwound healing. Exp cell Res 2005;304:274-86

Singer AJ, Clark RA. Cutaneous wound healing. N Engl J Med 1999;341:738-46

Skonier J, Bennett K, Rothwell V, Kosowski S, Plowman G, Wallace P, Edelhoff S, Disteche C, Neubauer M, Marquardt $\mathrm{H}$. Beta ig-h3: a transforming growth factor-beta-responsive gene encoding a secreted protein that inhibits cell attachment in vitro and suppresses the growth of $\mathrm{CHO}$ cells in nude mice. DNA Cell Biol 1994;13:571-84

Thapa N, Kang KB, Kim IS. Beta ig-h3 mediates osteoblast adhesion and inhibits differentiation. Bone 2005;36:232-42

Werner S, Grose R. Regulation of wound healing by growth factors and cytokines. Physiol Rev 2003;83:835-70

Yamada KM. Fibronectin peptides in cell migration and wound repair. J Clin Invest 2000;105:1507-9 
Yun SJ, Kim MO, Kim SO, Park J, Kwon YK, Kim IS, Lee EH. Induction of TGF-beta inducible gene-h3 (betaig-h3) by TGF-beta1 in astrocytes: implications for astrocyte response to brain injury. Brain Res Mol Brain Res 2002;107:57-64
Zhang K, Kramer RH. Laminin 5 deposition promotes keratinocyte motility. Exp Cell Res 1996;227:309-22 